\title{
GOVERNANCE OF THE AMMAN WATER UTILITY
}

\author{
$\underline{\text { R. Suleiman }}^{1}$, L. Van Well ${ }^{2}$ and J.E. Gustafsson ${ }^{1}$ \\ ${ }^{1}$ Department of Land and Water Resources Engineering, KTH (Royal Institute of \\ Technology), SE-100 44 Stockholm, Sweden \\ ${ }^{2}$ Institution for Infrastructure/ Urban Studies, KTH (Royal Institute of Technology), SE-100 \\ 44 Stockholm, Sweden
}

\begin{abstract}
In 1993 The World Bank assisted the Ministry of Water and Irrigation of Jordan in updating the water sector review and thus began the process of Private Sector Participation (PSP) for service provision. In this paper, three years of privatisation of water and wastewater services is examined and investigated from the stakeholder (input) and the consumer (output) perspective. The goal of the study is to assess the changes that have been taken place to date in relation to the principles of good governance. The results from interviews with stakeholders and questionnaires to consumers show that the privatisation process is so far only showing a few signs of "good" governance.
\end{abstract}

\section{KEYWORDS}

Good governance; private sector participation (PSP); privatisation.

\section{INTRODUCTION}

The Hashimite Kingdom of Jordan is of limited natural resources, small, lower middle-income, country with per capita income of about $\$ 1,700$, and a young population of about 5 million. More than $78 \%$ of the population lives in urban areas concentrated in the northern governorates of Amman, Irbid, Zarqa, Balqa. It is estimated that $38 \%$ of the population of Jordan lives in Capital Amman.

Jordan has relied principally on donors and creditors finical assistance to support the national economy and development programmes. Structural reform polices that are characterized by commercialisation of infrastructure provision has started on the mid of the 1990's including macroeconomic stabilization, trade and private investment, privatisation and sectoral reforms.

Jordan is an arid to semi-arid country that is facing a chronic imbalance in the water supply-demand equation. Water resources consist primarily of surface water, about $60 \%$, and groundwater and characterized by scarcity, vulnerability, variability, uncertainty and dependent on the amount of the rainfalls, which vary significantly spatially and temporally. Water resources are very limited, among, the scarcest of any country in the world. The expanding population due to natural and non-voluntary migration and the climatic and topographical conditions of the country have exerted enormous pressure on the limited water resources. Shortage and intermittence of urban supplies is getting severe. The available renewable water resources are about 780 with a total demand reaching about 1000 million cubic meters per year. The gap between water demand and water supply was covered by the unsustainable practice of overabstraction in both the renewable and fossil aquifers. Jordan has been implementing a water supply rationing program (Suleiman, 2003). During the summer period, the households receive 
Despite huge investments in the water sector, the country still faces a considerable water supply deficit and the gap is projected to be widening in the future. Thus, water is a precious resource that requires careful planning and prudent management.

The Ministry of Water and Irrigation (MWI), established in 1992, is the official body responsible for the overall water planning, management and the formulation of national water strategies and polices. Several donor organizations projects have assisted the MWI in the development of water policy, water master planning and restructuring of the water sector. Under direct authority of the MWI is the Water Authority of Jordan (WAJ), established as an autonomous corporate body with financial and administrative independence. The WAJ carries full responsibility for water and sewage systems and related projects in all of Jordan's Governorates.

The water sector has been constrained by lack of financial resources and insufficient cash flow coupled with a high level of subsidies. This has resulted in inadequate funds for the replacement and upgrading of water supply systems. Financial constraints have affected managerial aspects causing intermittent and uneven supply, loss of consumer's confidence, continued deterioration of water resources, increasing deficit in the supply demand equation, inadequate billing and collection systems, high non-revenue water and unaccounted for water. Inefficiency in administration, human resources development, and legislative issues were other drivers for policy reform. Thus the Ministry of Water and Irrigation was impelled to adopt remedy polices for restructuring and reforming the whole water sector to increase economic efficiency and to decentralize services under private sector participation (Workshop, 2002).

A bold water policy reform process was initiated in 1993. The process included cooperation with donor agencies in major efforts to restructure institutional frameworks, strengthen capacities, rationalize strategies, and widen public awareness and participation. More emphasis was put on increasing the commercial focus of operations, and accentuating the financial viability in water sector planning and operations.

Private sector participation (PSP) in providing services for infrastructure development is believed to be one way to make the water sector in Jordan more dynamic and financially viable. The transfer of infrastructure services delivery from the public to the private sector is also anticipated to improve performance and upgrade the level of the service and efficiency in the water sector. Hence the expansion of the role of the private sector with management contracts, leases, concessions and other forms of private sector participation in water utilities is largely envisaged.

\section{OBJECTIVES AND METHODOLOGY}

The objective of this study is to evaluate and assess the privatisation experience of the Water Authority of Jordan during 1999-2002 from a "good" governance perspective. The goal of the study is not to make a definite statement about the success or failure of the privatisation case, based on a three-year time period, but rather to evaluate the changes that are happening so far from the perspectives of stakeholder (or input) participation and consumer (or output) satisfaction. Is the process of privatisation of the water and sanitation services in Jordan leading the way to "better" governance?

Governance is a broad conceptual term that has been utilised to describe societal processes for achieving collective action in the realm of public affairs. It has been regarded as a tool to allocate, implement and regulate social and political actions. As a concept, governance extends beyond government in that it encompasses laws and regulations, as well as values and norms to mediate behaviour. In doing this, the concept of governance widens the circle of influential actors to include not only government officials, but also civil society and private sector. The World Bank (1992) conceptualises governance as "the manner in 
which power is exercised in the management of a country's economic and social resources for development". With regard to water, the Global Water Partnership in 2003 defined water governance as "...the range of political, social, economic and administrative systems that are in place to develop and manage water resources, and the delivery of water services, at different levels of society" (Rogers and Hall 2003). In this article we conceptualise governance with regard to water utility service provision as the process of designing (input) and implementing (output) effective and socially acceptable public policies and institutional frameworks by a mixture of public, private and civic actors.

In order to further specify the process of water governance, the article examines governance of the water sector in Jordan from a two-pronged perspective. First we discuss from an "input" or process perspective, the process of initial privatisation with a focus on the key stakeholders. Then we examine the "output" of the privatisation process in terms of service provision to consumers. Both of these stages are assessed in terms of several well-known parameters of "good governance".

Principles for "good" water governance, be it of the public sphere, private sector or a mixture of approaches have been conceptualised as Rogers and Hall (2003): 1) Openness and transparency, 2) Inclusiveness and communicativeness, 3) Coherent and integrated policy, 4) Equitability, 5) Accountability and 6) Efficiency. These principles of good governance are also echoed in the European White Paper on European Governance (CEC 2001) as openness, participation, accountability, effectiveness and coherence. The principles function as the operationalisation of "good" governance and as a yardstick by which to evaluate the governance process in the real world.

In terms of these "good" governance approaches, institutions for managing water should work in an open manner that can be understood by consumers and the public at large. Decision-making processes and outcomes should be transparent both to those inside the organization and outside of it. The inclusive and communicative approach aims at securing broad stakeholder participation in real terms. With the inclusion of a wide variety of stakeholders, policy will inherently be more integrative, but this runs the risk of wielding "dysfunctional" or incoherent policies, so efforts must be made to ensure that integrated policies or management retains sufficient bite, largely through strong leadership and responsibility, as well as efficient political bargaining. This entails a fine balance between essential "bottom-up" and "topdown" governance processes, which while desirable, are not always easy to achieve. Equity concerns are vital aspects of good governance, both intergenerational equity for future generations and well as intragenerational equity among socio-economic groups, gender and ethnic groups. The more operational approaches to good governance include accountability to the public and private sectors, citizens and consumers at large and not least to the wider legal and political systems in which the governance system is nested, but also efficiency of operation. Efficiency is usually conceived in terms of effective economic performance, but also includes overcoming bureaucratic stagnation and lethargy.

The research approach involved the use of qualitative research techniques. These encompass interviews with stakeholders involved in the privatisation process, including the Programme Management Unit (PMU) representing the privatisation project implementer, the water management company representing the private sector and the World Bank, the adviser and the promoter of the privatisation program, to determine how open, coherent and inclusive the policy process was. The WB role as main actor was evaluated from the interviews with the PMU and Lema. The PMU is supported and co-financed by the European Commission to manage the Greater Amman Water Sector Improvement Programme (GAWSIP) and possibly at later stages similar projects in other Governorates in Jordan.

The interviews were based on pre-structured but not necessarily standardized format of questionnaire with a majority of open-ended questions. The intention was to keep the focus on specific aspects of the privatisation process from both of the counterparts and to give the interviewee the opportunity to elaborate whenever thought necessary. The interviews involved a flexible and interactive, but still focused dialogue. To validate the collected data from the stakeholders, the informants were asked to review the draft reports of the interviews. 
In determining how effective and accountable the output of the privatisation is perceived, a standardized questionnaire of three main questions was addressed to a random sample of 360 residential subscribers located in the five districts of the Amman service area: south, north, west, east and middle. The total number of subscribers to water supply service was 265,000 and not less than $10 \%$ of the whole subscribers population was decided to be the total number of the sample survey. The sample represented the five areas equally and about $40 \%$ of the random sample was female. Out of the whole sample survey, $14 \%$ of poor income households, $18 \%$ were of high-income households and the rest were of average income households.

Residential consumers were asked directly to orally respond to a questionnaire and these responses were written down. The questionnaire includes a standardized set of questions that were set up to investigate the aspects of awareness on the involvement of the private sector, water prices raise and the consumer satisfaction on the increase, significance improvement of the provided service and in which specific area, in addition to information on the income of the household, gender type, number of household's members, and the average value of periodical bills that are distributed to each subscriber every three months. Both interviews and questionnaires were administered on site in Jordan in August 2002 by the first named author.

\section{PRIVATISATION AND POST PRIVATISATION SITUATION}

\section{Process departure}

In the beginning of the 1990s many countries, mainly from transition economies and developing countries embarked on privatisation studies to raise more money by pooling resources and improve efficiency.

In the case of Jordan, the Ministry of Water and Irrigation (MWI) invited the World Bank to assist it in updating the Water Sector Review of 1997 as an input into the formulation of a five-year action plan for the water sector. The review clearly emphasizes PSP for services provision. The shift towards privatisation for infrastructure delivery services in Jordan had started already in 1995. For the water sector, this shift -as conservatively and carefully stated by the interviewees (Al Naouri; Kefaya, 2002)was a condition or a preferred option to get the World Bank loan. The World Bank's role included a dialogue with the government during the initial preparatory stage, monitoring the implementation of the privatisation program and arranging with the government on how the role of the private sector should be developed.

Arthur Anderson (AA), a consultation services company, was primarily commissioned to prepare a statement of operation for the Amman Governorate Service Area (AGSA, the largest domestic water market in Jordan) and to advise a formula for calculating the operator variable fees. AA's report was used as the basis for preparing the terms of references for the Management Contract (MC) and enclosed in the bidding documents. On February 2, 1999 Suez Lyonnaise des Eaux, the international French water management company represented by the Lema consortium, won the water and wastewater MC for Greater Amman following an international call for tender. The consortium beat the sole competitor, Vivendi (Hall, et al., 2002). The service area caters to approximately 260,000 subscribers in which water coverage is $100 \%$ (Griffin, 2002; Hall, et al., 2002). Sanitation services are provided to about $75 \%$ of the people through network connections (Griffin, 2002).

In March 1999, following the awarding process, the World Bank approved a USD 55 million loan to Jordan to improve the efficiency, management, operation, and delivery of water and wastewater services and to support investment and rehabilitation tasks of the existing water plants and networks managed by Lema. A special Programme Management Unit (PMU) has been set up by the MWI within the WAJ to act as a contract administrator and quasi-regulator. 
The contracted terms of reference defined the main responsibilities of the private company as: 1) to operate the facilities and maintain them to improved standards, and 2) to carry out all billings, collections and improve customer service functions. The operator should also cooperate with WAJ in recommendation and implementation of the capital investment program. A program has been set up to rehabilitate and expand the water networks in the AGSA, of which it investment is estimated to USD 200 $\mathrm{M}$, financed by different donors including the WB, European Investment Bank and the USAID. Operator performance is measured by specific targets over the four-year contract period. The most important of these are associated with standards of unaccounted for water, accounts receivable and constancy of water supply. Having assigned these tasks, the operator has the right to access an annual fixed fee and other variable fees that are contingent on improved financial performance, operational efficiency based on the performance standards and net incremental cash flow. Auditors carry out financial and technical measures of operator performance to calculate penalties in case of violation.

\section{Paving the road to privatisation: changes in the tariff system}

Tariff setting lies within the mandate scope of the Prime Minster Cabinet. Until recently, water and sewerage tariffs were not sufficient to cover the cost of operation and maintenance (Griffin, 2002; Hall et al., 2002). Prior to the private sector involvement, a major change in the entire charging mechanism of tariffs took place from October 1, 1997. The change in the water tariff mechanism and the incremental increase in charges to recover the costs were based on the WB's recommendations (World Bank Group, 2001) and favoured polices that are cited by its publications (Idelovitch and Ringskog, 1995).

The mechanism changed from a progressive block tariff structure of six water consumption blocks of a fixed charging rate each, for both residential and commercial consumers to a two-part system tariff: volumetric lifeline rate for water consumption block of 20 cubic meter or less (fixed charges) and water use charges proportional to consumption. Commercial consumers in accordance to the new tariff system are being charged at a higher rate. The revamped tariff was expected to increase the revenues of the Service Area and offset the deficit of the financial balance sheet of the Water Utility. The tariff system doesn't directly subsidize any category of people. However, poor people are crossly subsidised by the commercial users and the wealthier residential consumers who presumably consume more water and thus charged higher.

The new mechanism imposes high tariffs on commercial users and has resulted in critical environmental consequences. Big hotels and commercial enterprises have started supplying their own water through water tankers. They are thus able to buy water cheaper and avoid paying wastewater charges when they are no longer metered. The tanker water is abstracted from unregulated groundwater private wells (Al Naouri, 2002; Hall et al., 2002), at the expense of sustainable yields of the groundwater aquifers. Since privatisation and until August 2002, no substantial increase in the tariff has occurred except for the sewage charges that were increased by $12 \%$ to recover the cost of investment in a newly constructed sewerage plant. However, a policy based on the World Bank guidance (World Bank Group, 2001), was approved to increase the tariff by $5 \%$ each year for the next five years in order to cover partially or totally the capital cost of new investments in the network (Alqam, 2002; Griffin, 2002). In its 2001 Water Sector Review Update, the World Bank wrote concerning Jordan: "In view of the significant size of investment needs (up to 5\% of GDP in some years), and the pace of mobilization of donors and investments, Jordan will have to redouble its efforts at generating significant additional operating income from drinking water supply and irrigation services. Urban water and irrigation tariffs have not increased since 1997. Urgent action is needed on tariffs to ensure full recovery of operating costs and periodic adjustment for inflation." The WB had quoted three options for tariff increase implementation from which the MWI had approved one. 


\section{IS “GOOD” WATER GOVERNANCE BEING ACHIEVED?}

Our question is how has the privatisation process of the water sector in Amman corresponds to the global call for "good "water governance in terms of the principles of openness and transparency, inclusiveness and communicativeness, coherent and integrated policy, efficiency, accountability and equity. The section below presents preliminary findings and analysis for three years of operation from the stakeholder (input) and consumer (output) perspectives.

\section{The stakeholder outlook}

Inclusiveness and communicativeness. The consultation process of the Greater Amman privatisation has primarily involved "selected" stakeholders, such as government commissioned consultants and institutions, donors and the private sector. The World Bank as financer of the project obviously had a vital role as catalyst. Water provision governance is no longer a regional or local question, but one that includes a plethora of stakeholders, including international organizations such as the World Bank, as well as private and public interests. Though said that privatisation was not imposed but rather a condition to access the WB loan, there may be little difference between condition to a loan and imposing an option if the borrower has a dire need. The World Bank's inclusion in the privatisation process significantly impacted polices questioning the needed balance of power to achieve viable partnership (Elander, 2002).

Efficiency and accountability. In the interviews, the Lema Executive Director said that Lema management has been efficient and the responsibilities are clear for the contractual parties. The efficiency of the operation and management of the water system is often measured in terms of the achievement of the particular performance standards. The integrated international experiences combined with the local knowledge enabled Lema to offset the losses of the former public utility and achieve a positive cash flow (Carton, 2002). The involvement of the private company as well as the investment fund has been important to improve the service provision. From Lema's perspective, it achieved 1) improvement in water quality, 2) reduction of power consumption, leakage responses- to which extent the Lema has been responsive to complaints of pipe leakages and repairs to reduce water losses-and the no-water response times, 3) improvements in customer relations. The no-water response time is the time needed for the customer service department at the Lema to respond to complaints that water is not supplied to the household according to the set up water supply schedule in the Amman Service Area.

From the PMU staff perspective, the criteria for the private sector performance were quite different and related to accountability of the water supply, both during the privatisation process and as an outcome for service provision. The principal accountability criteria for PMU was: 1) Constancy of supply, 2) The percentage of unaccounted for water (UFW)-the percentage of water losses by pipes leakages and illegal usage to water produced-and 3) and the accounts receivable. According to the contractual obligations, the target was that water supply should meet or exceed 24 hours per a week per subscriber, but Lema has argued that it is rather 24 hours a week per zone. The level of unaccounted for water was projected to $53 \%$ in the base year 1999. The target for the operator was that it the level of unaccounted for water should be $25 \%$ or less by the end the MC. In reality, what has been achieved is a reduction of unaccounted for water by $5-7 \%$, which has then been kept constant in the second and the third operating year. A representative from the PMU commented, "Frankly speaking, it is not possible for Lema or any other company to achieve the stipulated targets before the restructuring and the rehabilitation of the whole network, capital investment program. However, this company had accepted and approved the contractual conditions of the bid and they should comply. Many companies quitted the bid because they knew how it would be hard to accomplish the targets" (Al Naouri, 2002).

Accounts receivable is another important issue and one of the factors that complicate water governance. As of 2002, the private operator had not been able to accomplish the stipulated target, the integration of non-paid water delivered to the government agencies and the army, which still have due bills of about 4 million Jordanian Dinars (JD) that is equivalent to $\$ 5.7 \mathrm{M}$, and put forward many reasons for this non- 
compliance. Indeed it appears a quite ambitious target from the state side. How can the private operator create the political will needed to enforce governmental agencies to pay for water? This can only be accomplished by the representative governmental authority, the Water Authority of Jordan, as private sector participation cannot compensate for institutional inefficiencies on the part of the public sector (Rivera, 1996). Private sector involvement cannot of itself and by itself remove many of the barriers to efficiency, which impedes public sector operation (Rees, 1998)

Coherence and Integration. Despite the existence of the PMU as a semi-regulatory body, the water sector still lacks the framework that constitutes the appropriate regulating strategies (Kefaya, 2002). Furthermore, many obstacles have undermined the achievement of an effective progress. The Lema administration has articulated these obstacles as: 1) delays from the government side regarding the capital investment program, 2) delays in the delivery of the customer's information system (Carton, 2002) and 3) the inherited employees from the public sector and the inherited legacy of long and bureaucratic procedures. Because of Lema's limited authority, it must refer to the PMU in every little matter (Griffin, 2002). Other bottlenecks were lack of standardized interpretation and restriction of by-laws, and the high level of bureaucracy (Workshop, 2002). These obstacles were reiterated in principle by the PMU, but added others such as consumers who do not readily pay their bills, illegal users, and the poor situation of the water and sanitation network. Nevertheless, the PMU asserted that the Lema lacks the will to improve the performance, although it is well compensated. The Customer Service Director of Lema pointed out that coherency could perhaps be improved even more if there was a way to overcome these obstacles (Griffin, 2002).

The relationship between the contractor Lema and the PMU appears to be somewhat tense, due to contention regarding the degree of the independence of the contractor in relation to the contract administrator, progress and achievement of the performance standards, and contractual obligations and liability. Each entity has the tendency to attribute slow progress to the other's failures. Lema blames the relatively slow pace of unaccounted for water and receivables account standards on the PMU's reluctance to deliver the capital investment program and the new customer information system (CIS) to them. The PMU; however, asserts that the performance targets, as they have been contracted, have nothing to do with the capital investment program or the new CIS.

From the stakeholder perspective, coherence and accountability in terms of responsibility, are perhaps two of the most crucial aspects of striving for "good" water governance. The tension between the PMU and Lema, as well as the tendency for each to blame the other for problems in the supply of water is but indicative of one of the drawbacks of a wider, polycentric governance perspective. As the number of stakeholders increases, there can be confusion as to the role and responsibility each individual stakeholder assumes in the process. Methods to achieve coordination, coherency and complementarity are thus vital to create responsible, but dynamic synergies among the various actors (Global Water Partnerships 2003). The Global Water Partnerships Status Report to the $3^{\text {rd }}$ World Water Forum in 2003 suggests the concept of integrated water resource management (IWRM) as one such method and the introduction of stakeholder dialogues to facilitate communication among actors. Another method to increase responsibility and coherence among stakeholders is to boost the institutional capacity at the local and national level for the governing of water resources. Solving the tension between Lema and the PMU would entail intervention, either internal or external, in order to increase the capacity for the two entities to engage in constructive dialogue.

\section{The consumers outlook}

Openness and transparency. The consumer outlook regarding the services provision by Lema was investigated through a questionnaire in order to measure the impact of Lema's activities on the customer satisfaction level. One question investigated in the questionnaire was to scrutinize the extent that the public is aware and involved in the privatisation process. Surprisingly, 30\% of the customers were still unaware of the government strategies of privatisation. To the question if water prices had been raised in 
the last three years, results showed that $79 \%$ of consumers had been aware of an increase and $73 \%$ of the consumers felt that the increase in price was unacceptable.

When the first 5\% incremental increase of the water tariff was instigated in October 2002, consumers were neither appropriately consulted on this issue from the state nor informed about the increased tariffs from the private company. However newspapers informed customers of the cost of the project and mentioned this as the reason for increased tariffs. Thus while being tacitly informed of the process of privatisation, customers still were held outside of the participatory process. Roger Griffin of Lema alleged that the water contractor is not obligated to disseminate any specific information to the water consumers aside from bills, and information about changes in the rationing water supply program. Lema feels that the task remains within the public realm. Griffin stated in an interview "transparency needs to be a political decision. Personally I don't mind and I am transparent with customers when they come to ask about a certain issue or complain, but I do this not as an obligation". Lema and the PMU claimed that detailed information about the charging formula is not easy to be understood by the consumers (Griffin; Kefaya, 2002).

Lack of transparency and access to information in the public domain appears to have impeded the participation of civil society. Thus with the lack of more informal actors in the process, important "watchdog" functions failed to materialize. For instance, there were no public awareness campaigns of programs conducted prior to the privatisation to inform the public about the potential positive or negative effects of the process. But whose responsibility is it to ensure that transparency of decision-making and accessibility of information? Increasing public participation in such processes can be difficult, especially in countries and regions where there is no enabling political environment for participation or opportunities to get involved in the process by which decision are made.

Transparency and public accessibility to information appeared not be a large concern to Lema as a private company. As previously stated by Roger Griffin of Lema, this type of concern is dependent on a political decision. The Global Water Partnership (2003) has linked good governance with democracy, political system and sovereignty. While, it is not our focus to go deeply and investigate this link we recognise that a functioning participatory democracy is a key to enabling people to participate.

Water is a human right, as recognized by international law. Thus each state constitution must guarantee this right and ensure that the water governing process is effective, equitable, accountable and open and transparent. In doing so, the state should bear the responsibility to keep people informed and design and implement the socially appropriate methods for public participation. Public awareness campaigns, consultation, public discussion forums, and workshops should not be done to only to cosmetically drive evidence that public is involved in the governing process. Such an approach would have very little and short-lived impact in terms of number of consumers and their appropriate representation. The state has to embark on wide-scale and open consultations with the public and allow eventually for a broad debate of the water governance process to promote democratic participation, transparency and accountability.

Efficiency and accountability. The quality and the level of service provided are an important aspect in the evaluation process of the performance of the Water Company. About 60\% of the respondents' base did not notice any particular improvements associated with services provision, while $40 \%$ believed that there was an achieved improvement of efficiency. Of those that deemed that an improvement in water services had been met, $80 \%$ of these felt that this had occurred within the area of regularity of supply. It was stated repeatedly in the interviews with stakeholders that one of the main objectives of the privatisation project is to improve the customer services and relation. However, the questionnaire results show that the operator has only achieved some advancement in terms of the regular accessibility of water supply, but fairly little in the efficiency of billing operation and in gaining an ear for the various complaints. 
Equity issues. Access to basic water requirements has fluctuated in international discourse from being a basic human need and a right according to Salman M.A. and McInerney-Lankford (2004) and current thinking also includes water as a commodity of economic value. Thus in light of greater private sector involvement, the challenge is striking a balance between these interpretations (Salman M.A and McInerney-Lankford 2004). Nonetheless whether water is seen as a social good, an economic good or a human right, equity or fairness issues are intuitively important in the governance of their provision. . While the questionnaire to consumers did not specifically address equity matters, a few observations can be made regarding equity by the analysis of the provided data and the consumer questionnaires results. On one hand, $13 \%$ of subscribers consume less than $10 \mathrm{~m}^{3}$ of water, while they pay the full fixed tariff block of $20 \mathrm{~m}^{3}$. The set price for this block is less than the real cost and subsidised by the other segment of subscribers, but the consumers of this block are not benefiting from the subsidy. On the other hand, many low income households pay extremely high water tariffs since they use the same single water meter to avoid connection fees, and as the water tariff rises exponentially after $20 \mathrm{~m}^{3}$, their real cost of water is dramatically higher.

Fairness in the regulatory frameworks and enforcement is one important dimension of equity and ethical principles. Although complaint's offices that are authorised by the Ministry are open to consumers, it is only people of low social and non-influential status who usually go through the set up standard procedures. The powerful groups in society have the personal contacts resources to solve their issues individually and thus normal regulations and penalties do not always apply. In such a case, the private sector cannot create an enabling social system within which it can efficiently operate, instead the private sector has to adapt to the existing customs.

\section{CONCLUSION}

In conclusion, examination of good governance aspects in this three-year study of the privatisation process reveals that "good" governance is still being sought within the Amman water utility. On the one hand, lack of transparency, exclusion of the consumers in consultations stages, non-existing awareness programs, complications in the regulatory and cooperation tasks between the two counterparts, and accountability problems are all clear. On the other hand, neither does operational efficiency of water provisions appear to have increased, although accountability in terms of regularity of supply was perceived to have increased.

This is hardly surprising. Privatisation of services does not release the public sector from its responsibility for transparency, fairness of pricing and accountability for coherent policy. If the World Bank is concerned about achieving benefits on the ground, its focus on privatisation programs should not only include the increase in tariff charges but should also include a careful examination of the institutional capacity of the public-private partnership, and its transparency, accountability, coherence and fairness, in order to ensure that good governance will result. If such studies conclude on the feasibility of this management form, implementation should incorporate a real consultation process involving all actors and represents all interests. Privatisation cannot be a replacement to public responsibilities, but rather a complement under the condition of good governance. The partnership could then benefit by being more responsive to all stakeholders' concerns and interests.

The high imposed water tariff on commercial users and the functioning subsidy tariff system has shown the necessity of further investigations and research about the charges in order to adjust the water structure tariff appropriately, and to avoid discriminatory tariff regimes that could lead to undesirable environmental, social and economic inequity consequences. 


\section{REFERENCES}

Al-Naouri, J. (August, 2002). Personal Communication, Program Management Unit, MWI, Technical Manager of Management Contract. Amman, Jordan

Alqam, I. (August, 2002). Personal Communication, Ministry of Water and Irrigation. Cost and Tariff Section Head. Amman, Jordan

Carton, P. (August, 2002). Personal Communication, Lema Water Company, Executive Director. Amman, Jordan

CEC. (2001) White Paper on European Governance, COM (2001) 428 Final, Brussels, 25.7.2001.

Elander, I. (2002) Urban Partnerships. International Social Science Journal, 172: 191-204.

Global Water Partnership (2003) Effective Water Governance: Learning from the Dialogues. Status report prepared for the 3rd World Water Forum, Kyoto, Japan, March 16.23, 2003.

Griffin,R . ( August, 2002). Personal Communication, Lema Water Company, Customer Service Director. Amman, Jordan

Hall, D, and Bayliss, K,and Lobina, E.(2002) Water in Middle East and North Africa (MENA)-Trends in Investment and Privatisation. Public Service International Research Unit (PSIRU), UK.

Idelovitch, E. and Ringskog, K. (1995). Private Sector Participation in Water Supply and Sanitation in Latin America. The World Bank Washington, D.C.

Kefaya, J (August, 2002). Personal Communication, Program Management Unit , MWI, Director of Management Contract. Amman, Jordan

Rees J. (1998) Regulation and Private Participation in the Water and Sanitation Sector. Global Water Partnership, TAC Background papers No 1.

Rivera, D. (1996) Private Sector Participation in the Water Supply and Wastewater Sector, Lessons from Six Developing Countries. The World Bank, Washington D.C.

Rogers, P. and Hall, A.W. (2003) Effective Water Governance. TEC Background Papers, Global Water Partnership technical Committee (TEC). Stockholm.

Salman, M.A. and Mc Inerney-Lankford, S. (2004) The Human Right to Water: Legal and Policy Dimensions. The World Bank, Washington D.C.

Sluleiman, R.(2003). Water Resources Development in the Jordan River Basin in the Hashemite Kingdom of Jordan. The 3rd conference of the International Water History association, 11-14 December 2003 Bibliotheca Alexandria

The World Bank Group (2001) The Hashemite Kingdom of Jordan Water Sector Review Update Main Report. Rural Development, Water and Environment Group and Infrastructure Development group, Middle East and North Africa Region, Report No 21946-JO.

The World Bank Group. It accessed at www.worldbank.org/jo on March 2005.

Workshop. (2002). Private sector participation in the Jordan water sector, Annex 1-19. Amman, 16-17 April 2002

World Bank (1992), Governance and Development. Washington D.C.: World Bank Report 